Open Access

\title{
An exploration of strategies used by Chinese graduate students in electrical engineering and education: integrating questionnaire, task performance, and post- task recall data
}

Jessie Zhou and Li-Shih Huang*

\footnotetext{
*Correspondence: Ishuang@uvic.ca Department of Linguistics, University of Victoria, Clearihue Building, Room D356, 3800 Finnerty Road, Victoria, BC V8W 4P6, Canada
}

\begin{abstract}
This study was designed to examine the reported and observed communication strategies used by Chinese English-as-an-additional-language (EAL) graduate students in electrical engineering and education in performing informal debate tasks. The strategies were elicited through strategy inventories, post-task strategy recalls, and task performances. The results revealed eight categories of communication strategies, with fluency-oriented strategies used most frequently and translation least frequently. Differences in using communication strategies were also found between advanced and high-intermediate learners, while the use of one individual strategy-clarifying stance-also notably differed between the two disciplines. Overall, results from nonparametric tests revealed significant positive relationships between certain categories of communication strategy use and learners' speaking performance. The findings and their implications are discussed both to inform practice and to encourage further research about the communication strategies used by EAL learners who are graduate students.
\end{abstract}

\section{Introduction}

According to Immigration, Refugees and Citizenship Canada, the number of international students pursuing higher education in Canada continues to rise sharply, increasing most recently in 2016 by 22\% (268,631 students) (Kennedy, 2017). The Canadian Bureau for International Education (2016) has also reported strong growth in Canada's international student population, rising 92\% between 2008 and 2015 (http://cbie.ca). Among these students, the greatest growth has come from China and India, representing 49\% of all new students entering Canada in 2016; China also remains the largest among the top 20 sending markets to Canadian educational institutions (Kennedy, 2017). Research involving English-as-an-additional-language (EAL) students studying at North American universities has indicated that among the various challenges experienced by Chinese graduate students in their academic studies, speaking challenges are a top concern (e.g., Huang, 2012; Huang, 2004, 2005; Myles, Qian, \& Cheng, 2002; Sun \& Chen, 1999; Wan, 2001). Finding ways to help these students

(c) The Author(s). 2018 Open Access This article is distributed under the terms of the Creative Commons Attribution 4.0 International License (http://creativecommons.org/licenses/by/4.0/), which permits unrestricted use, distribution, and reproduction in any medium provided you give appropriate credit to the original author(s) and the source, provide a link to the Creative Commons license, and indicate if changes were made. 
become aware of their challenges in speaking English and develop their oral-language production in academic speaking contexts has thus become a vital area of concern. Researchers in second language acquisition have acknowledged that communication strategies can help learners compensate for their target language deficiency (e.g., Bialystok, 1990; Canale, 1980; Dörnyei, 1995; Faucette, 2001). More specifically, research has supported the idea that second language (L2) learners can improve their speaking effectiveness by developing their ability to orchestrate the use of particular communication strategies in response to the tasks at hand (see Macaro, 2006). Strategic competence, or knowledge of verbal and nonverbal communication strategies, is also included in the language ability models or communicative competence models proposed by numerous theorists (see Fulcher, 2003).

Since the 1970s, a large number of studies have recognized the potential benefits of communication strategies for L2 learners. Early studies (e.g., Færch \& Kasper, 1983; Selinker, 1972; Tarone, 1981) generally focused on defining and classifying communication strategies. Later researchers delved into variables that may influence which strategies are chosen, such as gender (e.g., Baker \& MacIntyre, 2003), language proficiency (e.g., Paribakht, 1985; Tan, Nor, \& Mohd, 2012; Yang \& Gai, 2010; Yoshida-Morise, 1998), and motivation (e.g., Brown, 2013; Guhlemann, 2011). The past three decades have also witnessed an emerging body of research on Chinese students' use of communication strategies (e.g., An \& Nathalang, 2010; Chen, 1990; Wang, 2000; Yang \& Gai, 2010). These studies, however, have mainly reviewed communication strategy research or focused on the general strategies employed by Chinese undergraduate students in local contexts. Limited attention has been given to (a) Chinese students' use of communication strategies at the graduate level in an English-speaking country; (b) the relationship between strategy use and speaking performance; and (c) similarities or differences between communication strategy use by learners in different disciplines, such as Electrical Engineering (EE) and Education (ED), which are among the most popular disciplines pursued by Chinese graduate students. For the former, speaking has been identified as a key area of challenge (e.g., Chen, 2006; Kassim \& Radzuan, 2008; Myles, 2009), whereas for the latter, the demand for an advanced command of English is usually prequisite for admissions. We therefore designed this study to contribute to the important effort of exploring how Chinese EAL graduate students majoring in EE and ED in a North American university use communication strategies and how these relate to speaking performance.

\section{Literature overview}

\section{Definitions and classifications of communication strategies}

The term communication strategies was first coined by Selinker (1972) in his influential theory explaining the processes involved in interlanguage (refer to Lennon, 2008). Selinker regarded communication strategies as one of five processes directly affecting the output of the interlanguage system, namely, language transfer (i.e., interlanguage transferred from the first language), transfer-of-training (i.e., interlanguage derived from the way learners are taught), strategies of L2 learning, strategies of L2 communication, and overgeneralization of target language linguistic material (i.e., of rules and semantic features) (Selinker, 1972). Corder (1983) further defined communication strategies as "a 
systematic technique employed by a speaker to express his or her meaning when faced with some difficulty" in dealing with linguistic problems (p. 16).

Tarone (1981) later observed the interactive trait of communication strategies and regarded the interactive feature-"a mutual attempt of two interlocutors to agree on a meaning in situations where requisite meaning structures are not shared" (p. 288) -as an important parameter in defining these strategies. Færch and Kasper (1983) later adopted a psycholinguistic approach to considering communication strategies as "potentially conscious plans for solving what to an individual presents itself as a problem in reaching a particular communicative goal" (p. 36). For Bialystok (1990), however, such strategies might be used in situations where no problems had arisen. Bialystok's work is also important for pointing out that the various definitions of communication strategies appear to share three main features: problematicity (i.e., recognizing a communication problem), consciousness (i.e., consciously using strategies to achieve communication goals), and intentionality (i.e., selecting a range of strategies to achieve communication goals). For this study, we specifically operationalized the term as the reported and observed strategic behaviours of EAL users when dealing with communication problems in completing a common interactive speaking task involving the free exchange of thoughts and opinions (see Tyler, Takada, Kim, \& Marinova, 2005).

As with definitions, categorizations of communication strategies also vary (e.g., Bialystok, 1990; Færch \& Kasper, 1983; Nakatani, 2006; Tarone, 1981), the limitations of which the literature has also extensively discussed (e.g., Ellis, 1994; Yang \& Gai, 2010). Among the most commonly referred to strategy classifications, Tarone's (1981) included paraphrasing (e.g., approximation, word coinage, and circumlocution); transfer (e.g., literal translation and language switch); asking for assistance (e.g., asking for assistance from the interlocutor); mime (e.g., nonverbal strategies); and avoidance (e.g., topic avoidance and message abandonment). Færch and Kasper (1983), on the other hand, categorized communication strategies into two groups: avoidance (e.g., topic avoidance, message abandonment) and achievement (e.g., code switching, interlingual transfer, and miming or appealing for assistance). Meanwhile, Bialystok's (1990) classification of communication strategies used in dealing with lexical, phrasal, and syntactical gaps divided them into L1-based (e.g., linguistic switch, foreignizing, and transliteration) and L2-based (e.g., substitution, description, and word coinage) strategies.

More recent notable clarification has been the Oral Communication Strategy Inventory (OCSI) developed by Nakatani (2006), which encompasses eight strategy categories with 32 items for coping with speaking problems, and seven strategy categories with 26 items for coping with listening problems. The eight categories in the speaking section consist of the following strategy types: (a) social-affective (i.e., strategies to manage affective variables in social contexts); (b) fluency-oriented (i.e., strategies to achieve fluency of communication); (c) negotiation of meaning (i.e., strategies for negotiating meanings with interlocutors); (d) accuracy-oriented (i.e., strategies to achieve accuracy in communication); (e) message reduction and alteration (i.e., strategies for navigating or avoiding communication breakdowns); (f) non-verbal (i.e., use of eye contact, gestures, or facial expressions in communication); (g) message abandonment (i.e., learners giving up their attempt to communicate when faced with difficulties); and (h) attempts to think in English (i.e., learners thinking as much as possible in the target language during communication). Since publication, the OCSI has been used to investigate 
communication strategy use across several countries (e.g., Brown, 2013; Chen, 2009; Saziyen \& Pelin, 2013; Teng, 2011).

\section{Research exploring key variables related to use of communication strategies}

A wealth of research has also examined learners' strategic behaviours vis-à-vis language performance, including various studies focusing specifically on communication strategies (e.g., Liskin-Gasparro, 1996; Nakatani, 2006; Paribakht, 1985; Peacock \& Ho, 2003). For example, Liskin-Gasparro's (1996) study examined 17 high-intermediate and 13 advanced learners' use of communication strategies in Spanish. The results indicated that high-intermediate speakers favoured L1-based strategies while advanced speakers relied on a range of L2-based strategies. Nakatani's (2006) work, which involved developing the OCSI and included large sample sizes at all three phases of development and validation, showed that overall, undergraduate Japanese learners of English with high proficiency reported using more strategies in the social-affective, fluency-oriented, and negotiation-of-meaning categories than did low-proficiency learners. The latter also appeared to rely more on message abandonment strategies for dealing with speaking problems.

Studies further exploring the relationships between general learning strategy use and academic disciplines have suggested that students in different majors tend to choose different strategies. For example, Chang (1991) reported that EAL students in the humanities and social sciences generally reported using more strategies than did science majors. Mochizuki (1999) suggested that academic subject was a key variable associated with choice of strategies reported by Japanese university students. The largest study investigating this variable to date has been that of Peacock and Ho (2003) involving over 1000 university EAP (English for academic purposes) students in Hong Kong across eight disciplines. The results also suggested disciplinary variations in strategy use, prompting the researchers to propose discipline-specific strategy training. Ann and Nathalang's (2010) study involved Chinese first-year undergraduate students from the arts and sciences at a Chinese university; although devoid of observed strategy use owing to data collection methods, the study similarly revealed differences in strategies between learners from the two disciplines.

Another variable potentially affecting the nature of interactions between learners and strategies used to complete tasks is task type (e.g., Ann \& Nathalang, 2010; Ghout-Khenounce, 2012; Khan \& Victori, 2011; Macaro, 2006; Rossiter, 2003; Skehan, 1998; Smith, 2003). Task types frequently used by researchers include translation, storytelling, topic discussion, Jigsaw, role playing, decision making, and object description. Overall, research has suggested that task type potentially affects both the quantity and the quality of reported use of communication strategies, although with conflicting results. Scant research, however, has examined communicative tasks facilitating the negotiation of meanings specifically by academic graduate learners.

A review of the literature further reveals little research on how Chinese EAL graduate students in Canada use communication strategies and how their strategy use relates to performance on a common academic speaking task, namely, informal debates. This 
study therefore aimed to fill this void by exploring the use of communication strategies by Chinese EAL graduate students majoring in EE and ED in a Canadian university and the strategies' relationships to speaking performance. Specifically we examined the following research questions: (a) What communication strategies do Chinese graduate students majoring in EE and ED use? (b) Do high-intermediate and advanced learners differ in how they use communication strategies? (c) Do learners in the disciplines of EE and ED differ in how they use communication strategies? (d) How does the use of communication strategies relate to oral production?

\section{Methods}

Participants

The participants recruited for the study were 12 Chinese EAL graduate students at a Canadian university. All participants were full-time graduate students studying EE $(n=6)$ or ED $(n=6)$, but since one ED participant did not take part in the second task, that participant's data were removed from the analysis, leaving a total of five ED participants. All were from the People's Republic of China, with Mandarin as their first language and English as an additional language. Other information gathered from the background questionnaire included the participants' age, language-learning background, length of residence in English-speaking countries, and TOEFL (Test of English as a Foreign Language) or IELTS (International English Language Testing System) Speaking Test scores. The average age of the participants was 25. All participants learned English formally in China, with an average of 13 years spent learning English. None had any experience living or studying in another English-speaking country before going to Canada. The mean length of residence in Canada was 14 months. The participants' reported test scores used for graduate school admissions ranged from 20 to $22(M=20.4)$ on the TOEFL Speaking Test, and from 6.0 to $7.5(M=6.7)$ on the IELTS Speaking Test.

\section{Instruments}

In addition to the background questionnaire mentioned above, we also used the following instruments, considering the typical size of EAP speaking courses and the feasibility of tools that teacher researchers would be able to implement in their own teaching context:

1. Language pre-test: We administered an English language proficiency pre-test to corroborate the scores reported by the participants in their profile questionnaires and to ensure they were at the appropriate proficiency levels. The topic of the test was adapted from the TOEFL iBT topic pool and consisted of two parts: (a) a oneminute self-introduction, and (b) a one-minute talk on the following topic: "Some people think it is more fun to spend time with friends in restaurants or cafes. Others think it is more fun to spend time with friends at home. Which do you think is better? Explain why." Participants had one minute to prepare for both parts.

2. Oral Communication Strategy Inventory (OCSI): Given the focus of our study on the speaking domain, we adapted Nakatani's (2006) classification of the speaking 
section in the OCSI to elicit the oral communication strategies used by the participants to cope with their speaking challenges. The OCSI's speaking section consists of 28 items involving the following strategy categories: social-affective, fluency-oriented, negotiation of meaning, accuracy-oriented, message reduction and alteration, nonverbal, message abandonment, and attempt to think in English. These categories and strategies were reviewed and adapted to suit the context of this study. Because from a statistical perspective factors need at least three items to be considered generally strong and stable (Costello \& Osborne, 2005; Maroof, 2012), and because the "attempt to think in English" category comprised only two items, we relocated it to the instrument for post-task communication strategy recall (see below). For the nonverbal category, which also contained only two items, we divided the original statement "I use gestures and facial expressions" into two items and added the use of eye contact given the nature of the task, which involved managing taking turns. Other modifications included moving some items to more appropriate categories. For example, the item "I ask other people to help when I can't communicate well" was moved from message-abandonment to social-affective strategies following the categorization of the latter proposed by researchers in the literature (e.g., O’Malley \& Chamot, 1990). Similarly, the item "I try to use fillers when I cannot think of what to say" was moved from social-affective strategies to fluency-oriented strategies since researchers have highlighted the significance of using fillers to enhance fluency (e.g., Albino, 2017; Canale, 1983). A few items were removed because they did not fit the context or were repetitious. For example, the statement "I try to emphasize the subject and verb of the sentence" was removed from accuracy-oriented strategies since its interpretation could be encapsulated in the item "I notice myself following grammatical rules in expressing what I want to say" from the same category. In taking this modified version of the OCSI upon both recruitment and completion of the study, participants rated the strategies within each category using a 5-point scale ranging from 1 (never use) to 5 (always use).

3. Informal debate tasks: Participants carried out two informal debates on topics adapted from the speaking section of the TOEFL iBT topic pool, specifically, "It is better for children to grow up in the countryside than in a big city," and "It is better for students to live with local families than with friends when they study abroad." Informal debate was an appropriate task for the participants since its format is similar to the critical evaluation graduate students engage in as they present ideas demonstrating critical thinking during academic discussions. The dynamic nature of debates requires students to position their stance while simultaneously acknowledging others' viewpoints or arguments, and also to plan counterarguments with a logical line of thought (e.g., Hall, 2011).

4. Post-task communication strategy recall: Previous studies in communication strategy use (e.g., Brown, 2013; Saziyen \& Pelin, 2013; Teng, 2011) have primarily used questionnaires to elicit strategic behaviours, despite the limitations of selfreport and non-task-specific questionnaires. Therefore, to obtain a fuller picture of the participants' strategic behaviours, we asked them to immediately recall the post-task communication strategies they used in dealing with the challenges they encountered in performing the speaking task (Huang, 2010). 


\section{Data collection}

Pilot study

We first performed a pilot study involving two students from two disciplines to field-test the instruments and data collection procedures. Modifications made following the pilot study included (a) adjusting the time for completing the OCSI questionnaire, (b) selecting topics for the informal debate tasks, and (c) clarifying items on the OCSI questionnaire and post-task in response to the participants' feedback (e.g., providing examples of the term fillers and revising the item "I try to speak clearly and loudly to make myself heard" to "I try to speak clearly to make myself understood," since both students thought they never raised their voices to enhance or maintain fluency).

\section{Main study}

The main study included three data collection sessions, as summarized in Table 1, conducted on different days. The interval between Session 2 and Session 3 was one week.

\section{Data coding and analysis}

Two coders fully coded all transcribed recorded clips from the informal debate tasks. The task performance data were further coded directly from the video recordings to observe nonverbal strategic behaviours that were absent from the other sources of data (Huang, 2013). We used a coding scheme built on the work of Nakatani (2006) and others (see Swain et al., 2009) and derived from the data gathered for this study as the starting point for analysis (refer to Appendix for the coding scheme). The first coder independently coded $100 \%$ of all data gathered from the informal debate tasks and the entries for the post-task communication strategy recall. A second coder independently coded $100 \%$ of the post-task recall entries and $50 \%$ of the observed and oral production data from the informal debate tasks. The intercoder reliability score was $85.7 \%$. All coding disagreements were discussed until 100\% agreement was reached. Three weeks later, the first author coded $50 \%$ of the debate data and reached an intracoder reliability of $89.9 \%$. For quantitative data analyses, we conducted nonparametric statistical tests (see Pett,

Table 1 Data Collection Sessions

\begin{tabular}{lll}
\hline Session & Group & Procedures \\
\hline $\begin{array}{l}\text { Session 1 (20 min./ } \\
\text { group) }\end{array}$ & $\begin{array}{l}\text { • Ethics, language proficiency pre-test, OCSI 1 } \\
\text { Session 2 (55 min./ ED }\end{array}$ & $\begin{array}{l}\text { - Ethics, language proficiency pre-test, OCSI 1 } \\
\text { group) }\end{array}$ \\
& Background information questionnaire, oral production task 1-informal debate \\
& $\begin{array}{l}\text { topic 1, post-task communication strategy recall } \\
\text { - Background information questionnaire, oral production task 1-informal debate } \\
\text { topic 1, post-task communication strategy recall }\end{array}$ \\
$\begin{array}{l}\text { Session 3 (60 min./ ED } \\
\text { group) }\end{array}$ & $\begin{array}{l}\text { Oral production task 2-informal debate topic 2, post-task communication strat- } \\
\text { egy recall, OCSI 2 } \\
\text { - Oral production task 2-informal debate topic 2, post-task communication strat- } \\
\text { egy recall, OCSI 2 }\end{array}$ \\
\hline
\end{tabular}

Note. $N=11$. EE electric engineering, ED education, OCSI Oral Communication Strategy Inventory 
2016; Linebach, Tesch, \& Kovacsiss, 2014) using SPSS (Statistical Package for the Social Sciences) Version 20.

\section{Language proficiency pre-test and oral production data}

Two raters independently rated the recordings of the pre-tests using established scoring rubrics. The mean of two scores was calculated as the final score when the difference in ratings was less than or equal to 0.5 . The participants were then divided into two proficiency levels according to their pre-test scores: advanced $(n=5, M=3.8, S D=.10$, Max =3.9, Min = 3.6) and high intermediate $(n=6, M=3.2, S D=.20$, Max $=3.4$, Min $=$ 3). Two certified TESL instructors also rated the informal debate data following the same procedures as the rating of the pre-tests. Interrater reliability of the pre-test ratings and oral production data was assessed using Spearman's rho coefficient, with correlation coefficients (pre-test: $r_{s}=.872, p<.000$; oral production: $r_{s}=.838, p<.000$ ), both confirming high reliability. The relationship between the participants' pre-test and oral production scores were also strongly and positively correlated $\left(r_{s}=.933, p<.000\right)$.

\section{Strategy use data}

To answer the research questions, we quantitatively analyzed responses from the OCSI questionnaire, video-recorded data from the informal debate tasks, and written data from the post-task recall. The coded data were tallied and percentages of observed and reported individual strategies within each strategy category were computed for each participant for each task. After the descriptive statistics were tabulated for the first research question, the Mann-Whitney $U$ Test was performed to compare differences in use of communication strategies between participants at the two proficiency levels and in the two disciplines (questions 2 and 3). Next, Spearman's correlational analyses were used to examine the direction and magnitude of the relationship between strategies and oral production scores (question 4). Finally, the qualitative data from the post-task communication strategy recall were also analyzed thematically. Themes were derived inductively from the data using open coding, and all coding differences were resolved through discussion (Miles, Huberman, \& Saldaña, 2014). Our purpose was to understand the participants' perception of the challenges they encountered in performing the tasks and their corresponding solutions.

\section{Results}

\section{Quantitative analysis}

With respect to the first research question, regarding what communication strategies are used by Chinese graduate students majoring in EE and ED, we first conducted a Wilcoxon Signed-Ranks Test to determine any statistical difference between the OCSI completed by the participants when recruited and upon completing the study. The results indicated that none of the seven strategy categories reached statistical significance $(Z=-.052$ to -.979 , n.s.). We then used the means of the two OCSI scores for the participants' self-reported communication strategy use, which resulted in the following scores: social-affective $(M=3.95, S D=.42)$; 
fluency-oriented $(M=3.91, S D=.42)$; negotiation of meaning $(M=3.88, S D=.36)$; accuracy-oriented $(M=3.82, S D=.37)$; message reduction and alteration $(M=3.97$, $S D=.31)$; nonverbal $(M=4.00, S D=.44)$; message abandonment $(M=2.89, S D=.63)$. The OCSI results suggest that all participants were high users of all strategies (mean value of 4 on the 5-point scale, i.e., usually used), with the exception of message abandonment.

Among the 28 items on the OCSI, the following 10 were the most frequently reported individual strategies, with three in the fluency-oriented, three in the social-affective, and one each in the message reduction and alteration, negotiation of meaning, nonverbal, and accuracy-oriented categories:

1. I try to speak clearly to make myself understood: $M=4.41, S D=0.49$ (fluencyoriented)

2. I use words which are familiar to me to express what I want to say: $M=4.36, S D=$ 0.39 (message reduction and alteration)

3. I actively encourage myself to express what I want to say: $M=4.32, S D=0.51$ (social-affective)

4. I try to give a good impression to the listener: $M=4.32, S D=0.81$ (social-affective)

5. I give examples if the listener doesn't understand what I am saying: $M=4.23, S D=$ 0.52 (negotiation of meaning)

6. I try to enjoy the conversation: $M=4.18, S D=0.51$ (social-affective)

7. I try to make eye contact when I am talking: $M=4.14, S D=0.71$ (nonverbal)

8. I correct myself when I notice that I have made a mistake: $M=4.09, S D=0.54$ (accuracy-oriented)

9. I try to use fillers (e.g., um, uh, ah, ok, you know) when I cannot think of what to say: $M=4.09, S D=0.74$ (fluency-oriented)

10. I pay attention to my pronunciation: $M=4.09, S D=0.58$ (fluency-oriented)

We next analyzed the frequencies of individual strategies from the informal debate tasks (observed data) and post-task communication strategy recall (selfreported data) by strategy categories. Among the categories (Table 2), fluency-oriented (27.43\%) and accuracy (26.04\%) accounted for over half of all identified strategies. The use of accuracy-oriented strategies, however, showed great variation across participants $(M=46.09, S D=21.46, \operatorname{Max}=83, \operatorname{Min}=17)$.

Table 2 Identified Communication Strategy Categories

\begin{tabular}{lllllllll}
\hline & SocAff & Fluency & Negotiation & Accuracy & M-Alter & Nonverbal & M-Aban & Translate \\
\hline Mdn & 17.00 & 46.00 & 28.00 & 49.00 & 3.00 & 24.00 & 6.00 & 2.00 \\
M & 19.45 & 48.55 & 27.91 & 46.09 & 3.00 & 26.73 & 4.91 & 0.36 \\
SD & 6.86 & 17.31 & 14.05 & 21.46 & 2.32 & 13.16 & 3,86 & .67 \\
Frequency & 214 & 534 & 307 & 507 & 33 & 294 & 54 & 4 \\
Percentage & $10.99 \%$ & $27.43 \%$ & $15.77 \%$ & $26.04 \%$ & $1.69 \%$ & $15.10 \%$ & $2.77 \%$ & $0.21 \%$ \\
\hline
\end{tabular}

Note. $N=1,947$. Data sources: Informal debate tasks and post-task strategy recalls. SocAff social-affective, Fluency fluencyoriented, Negotiation negotiation of meaning, Accuracy accuracy-oriented, M-Alter message reduction and alteration, Nonverbal nonverbal, $M$-Aban message abandonment, Translate translation 
Among the 1947 total strategy frequency counts and 28 individual strategies identified in the two data sources (i.e., the informal debate tasks and post-task strategy recalls), the top 10 individual strategies (total frequency counts, mean, standard deviations, and percentages in relation to both their respective categories and to the total number of strategies used) were as follows:

1. Using fillers (fluency-oriented): ( $n=269, M=24.45, S D=10.07,54.37 \%, 13.82 \%)$

2. Correcting self (accuracy-oriented): $(n=269, M=24.45, S D=13.47,53.06 \%$, 13.82\%)

3. Referring to notes for fluency (fluency-oriented): ( $n=235, M=21.36, S D=10.89$, $44.01 \%, 12.07 \%)$

4. Referring to notes for accuracy (accuracy-oriented): ( $n=235, M=21.36, S D=$ $10.89,46.35 \%, 12.07 \%)$

5. Making eye contact (nonverbal): $(n=157, M=14.27, S D=8.15,53.40 \%, 8.06 \%)$

6. Gesturing (nonverbal): $(n=130, M=11.82, S D=8.40,44.22 \%, 6.68 \%)$

7. Yielding turns (social-affective): ( $n=116, M=20, S D=6.22,54.21 \%, 5.96 \%)$

8. Exemplifying (negotiation of meaning): ( $n=84, M=7.64, S D=4.13,27.36 \%$, $4.32 \%)$

9. Clarifying stance (negotiation of meaning): $(n=56, M=5.09, S D=2.35,18.24 \%$, $2.88 \%)$

10. Empathizing with others (social-affective): ( $n=56, M=5.09, S D=1.04,26.17 \%$, $2.87 \%)$

Regarding the second research question, of whether high-intermediate and advanced learners differ in how they use communication strategies, the Mann-Whitney test indicated that advanced participants used the following three strategy categories statistically more often than high-intermediate participants: social-affective $(p=.035)$, negotiation of meaning $(p=.035)$, and message reduction and alteration $(p=.033)$. Overall, both groups used fluency-oriented strategies (advanced vs. high-intermediate: $M=57.40$ vs. $M=41.17$ ), followed by accuracy-oriented (advanced vs. highintermediate: $M=56.60$ vs. $M=37.33$ ), while translation strategies were the least

Table 3 Communication Strategy Use by Category Showing Significant Differences between Advanced and High-intermediate Participants

\begin{tabular}{lllllllllll}
\hline Category & Proficiency & $N$ & $M$ & $\begin{array}{l}\text { Mean } \\
\text { rank }\end{array}$ & SD & Mdn $\begin{array}{l}\text { U } \\
\text { score }\end{array}$ & $\begin{array}{l}\text { Z } \\
\text { score }\end{array}$ & $P$ \\
\hline Social-affective & Advanced & 5 & 24.00 & 8.30 & 5.48 & 23 & 3.50 & -2.109 & $.035^{*}$ \\
& $\begin{array}{l}\text { High- } \\
\text { intermediate }\end{array}$ & 6 & 15.67 & 4.08 & 5.68 & 16 & & & \\
Negotiation of meaning & $\begin{array}{l}\text { Advanced } \\
\text { High- }\end{array}$ & 5 & 37.40 & 8.30 & 11.46 & 31 & 3.50 & -2.104 & $.035^{*}$ \\
& $\begin{array}{l}\text { intermediate } \\
\text { Advanced }\end{array}$ & 5 & 20.00 & 4.08 & 11.17 & 18 & & & \\
Message reduction and & 5 & 4.60 & 8.30 & 2.07 & 4 & 3.50 & -2.129 & $.033^{*}$ \\
alteration & $\begin{array}{l}\text { High- } \\
\text { intermediate }\end{array}$ & 6 & 1.67 & 4.08 & 1.63 & 1.50 & & & \\
\hline
\end{tabular}


frequently identified (advanced vs. high-intermediate: $M=0$ vs. $M=0.67$ ). The results also suggested that the advanced group used more negotiation of meaning strategies (advanced vs. high intermediate: $M=37.4$ vs. $M=20.0$ ) than nonverbal (advanced vs. high intermediate: $M=33.0$ vs. $M=21.50$ ), whereas the results for the high-intermediate group showed the reverse (see Table 3).

Overall, advanced participants used 1100 individual strategies while highintermediate participants used 847 such strategies. Only certain of these strategies were used more frequently by the latter than the former, namely, self-encouragement, empathizing with others, seeking clarification, chunking, facial expression, and translating. Among the 28 individual strategies, the most frequently used were self-correction (7.56\%) by advanced participants and fillers $(6.83 \%)$ by high-intermediate participants. Chunking $(0.15 \%)$ and translating $(0.21 \%)$ were two strategies uniquely used by high-intermediate participants, while correcting others $(0.15 \%)$ was uniquely used by advanced participants.

As for the third research question, comparing the use of communication strategies by learners in the EE and ED disciplines, the Mann-Whitney test results showed no statistically significant differences across all eight strategy categories. The most frequently identified were fluency-oriented (EE vs. ED: $M=49.67$ vs. $M=47.20$ ) and accuracy-oriented (EE vs. ED: $M=49.67$ vs. $M=41.80$ ), with more prominent use of negotiation of meaning (EE vs. ED: $M=25.83$ vs. $M=30.40$ ), nonverbal (EE vs. ED: $M=22.67$ vs. $M=31.60$ ), and social-affective (EE vs. ED: $M=16.83$ vs. $M=22.60$ ).

The only individual strategy reaching statistical significance between the EE and ED groups was that of clarifying one's stance $(Z=-2.211, p=.027)$, the ED group using it three times more frequently than the EE group. Though not statistically significant overall, the use of individual strategies between the two groups and within each group did vary across categories. For example, among the 28 individual strategies, the EE group used self-correction (8.94\%) and the ED group used referring to notes for accuracy (5.70\%) and referring to notes for fluency $(5.70 \%)$ most often. Within the category of fluency-oriented strategies, the EE group used fillers most often (EE vs. ED: $M=26.83$ vs. $M=21.60$, n.s.), whereas the ED group referred to notes most often (EE vs. ED: $M=22.20$ vs. $M=20.67$, n.s.). In the nonverbal category, the ED group used eye contact more frequently than gesturing, whereas the EE group used both strategies equally (eye contact: EE vs. ED: $M=11.17$ vs. $M=18.00$; gesturing: EE vs. ED: $M=11.17$ vs. $M=12.60$ ).

Finally, in examining the fourth research question, concerning relationships between use of communication strategies and oral production, we used Spearman's

Table 4 Correlation Between Communication Strategies by Category and Oral Production Scores

\begin{tabular}{|c|c|c|c|c|c|c|c|c|c|}
\hline & & SocAff & Fluency & Neg & Accuracy & $\begin{array}{l}\text { M- } \\
\text { redu }\end{array}$ & Nonverbal & $\begin{array}{l}\text { M- } \\
\text { aban }\end{array}$ & Translation \\
\hline \multirow[t]{2}{*}{$\begin{array}{l}\text { Oral production } \\
\text { scores }\end{array}$} & $\begin{array}{l}\text { Correlation } \\
\text { coefficient }\end{array}$ & $.616^{*}$ & $.661^{*}$ & $.765^{* *}$ & $.691^{*}$ & $.834^{* *}$ & .510 & .568 & -.284 \\
\hline & Sig. (2-tailed) & .043 & .027 & .006 & .019 & .001 & .109 & .069 & .397 \\
\hline
\end{tabular}

Note. Spearman's rho, $N=11$, SocAff Social-affective, Fluency Fluency-oriented, Neg Negotiation of Meaning, Accuracy Accuracy-oriented, M-redu Message Reduction and Alteration, Nonverbal Nonverbal, M-aban Message Abandonment

${ }^{*} p<.05 .{ }^{* *} p<.01$ 
rho test to analyze these at three levels: (a) participants' overall strategy use vis-à-vis oral production scores, (b) strategy categories vis-à-vis oral production scores, and (c) individual strategies vis-à-vis oral production scores.

Regarding strategy use vis-à-vis oral production scores, the results showed a statistically significant positive relationship overall between the identified frequencies of communication strategies and speaking scores in performing the informal debate tasks $\left(r_{s}=.727, p=.011\right)$. As for the strategy categories vis-à-vis oral production scores, the results also showed statistically significant relationships between oral production scores and the following strategy categories: social-affective, fluencyoriented, negotiation of meaning, accuracy-oriented, and message reduction and alteration (see Table 4).

Regarding individual strategies vis-à-vis oral production scores, seven individual strategies were positively correlated with participants' debate scores at the significance level, namely, yielding turns $\left(r_{s}=.690, p=.019\right)$, referring to notes for fluency $\left(r_{s}=.644\right.$, $p=.026)$, exemplifying $\left(r_{s}=.636, p=.035\right)$, clarifying meaning $\left(r_{s}=.680, p=.021\right)$, referring to notes for accuracy $\left(r_{s}=.664, p=.026\right)$, correcting others $\left(r_{s}=.607, p=.048\right)$, and message reduction and alteration $\left(r_{s}=.893, p=.000\right)$.

\section{Qualitative analysis}

To more readily follow participants' perceptions of the communication challenges they encountered and their corresponding solutions as elicited through the post-task communication strategy recall, the results are presented by speaking challenges, reflections on strategy use, and use of translation.

\section{Speaking challenges}

The participants were concerned about accurate self-expression, listening challenges in speaking, and vocabulary size. How to express themselves accurately and precisely was especially challenging for most of them. Regarding accuracy, nine out of $11(81.8 \%)$ participants struggled with "using proper word choices," "expressing clearly," "speaking accurately," "using correct grammar," and "describing figures and tables correctly." Eight (72.7\%) participants expressed a desire for "using accurate, authentic English." Indeed, the category of accuracy-oriented strategies was among the most frequently identified categories in the informal debate tasks. Lack of vocabulary was another dominant challenge identified by participants. Vocabulary size could play a role either participants' comprehension of others or the comprehensibility of their own expressions. The following excerpts from the post-task recalls illustrate the challenge:

The vocabulary and the talking habit are challenges for me. With limited vocabulary, it is difficult to make my talk/presentation/articulate vividly. ... Sometimes, I try to translate from Chinese to English, which makes my sentence strange. I don't have enough vocabularies to present my idea vividly. (P6, EE, Advanced)

Sometimes I would like to express something or some ideas, since my vocabularies are not rich enough, I could not use some proper and explicit words to express 
myself. During this procedure, the information conveyed will have some errors

between the initial meaning and the information listeners got. (P5, EE, Advanced)

Other challenges mentioned included fluency, accent, coherence, taking turns, and achieving syntactical complexity and grammatical accuracy, as the following examples illustrate:

Maintaining turns: "For me, I get my points to say, the thing is I don't have enough time to say. Interrupted by people. They are so active." (P10, ED, Advanced).

Grammatical accuracy: "I think I spend too much time on grammar like she/he, tense." (P2, EE, High-intermediate).

Coherence: "The problem is to organize the points in a logical order and stay that way." (P1, EE, High-intermediate).

\section{Reflections on strategy use}

Many participants frequently reported such common individual strategies as exemplifying (i.e., using examples), message reduction and alteration, and approximating. Furthermore, all participants mentioned that using certain strategies worked and could solve some problems they encountered in communication, though these were not necessarily "the best" solutions. For example, one participant said: "Yes, I think [elaborating] worked, but it may make the conversation less concise" (P11, ED, High-intermediate). Overall, negotiation of meaning was the most frequently reported strategy category, with exemplifying being the most frequently used individual strategy within this category; it was also among the top-10 individual strategies in relation to total number of strategies used in the informal debate tasks.

Approximating was another individual strategy commonly reported by participants. Participants replaced original expressions with similar but simpler expressions they felt comfortable with when encountering difficulties in communication. For example, one participant reported: "Sometimes it's hard for me to find a proper word to express myself clearly. So I may choose to use some simple words or synonyms to express" (P5, EE, Advanced). Social-affective strategies were also commonly reported by participants. Although the debate data showed hardly any instances--naturally so, due to the online nature of the speaking and the task's demands--of self-encouragement and lowering anxiety, in the post-task recalls participants reported being anxious in communicating with others in English and trying to overcome these negative feelings. For example:

Once you are getting so nervous in the conversation, try to relax but it is always hard. Because once you make a mistake, you will feel nervous. Once you feel nervous, you will make more mistakes. So just stop for a few seconds trying to adjust yourself and back to the right side. (P10, ED, Advanced)

Self-correction was another individual strategy frequently used by some participants. For example, one participant said: "When I realized the mistakes, I correct myself" (P9, ED, High-intermediate). Both self-correction and using fillers (which shared first place among all individual strategies) were most frequently used in 
the informal debate tasks. Overall, most participants $(81.8 \%)$ reported not using any translation strategies while speaking, although $36.4 \%$ took notes in Chinese while preparing, as the following excerpt illustrates:

Since the preparation time is limited, I would like to use the less time to convey the most information. I take some notes or write down the main points I'd like to say during the debate in Chinese. But in the procedure of the debate, I will not think and express in the Chinese way. I may switch to the English communication way. (P5, EE, Advanced)

Finally, message reduction and alteration and message abandonment strategies were two other solutions to communication challenges for some participants by ignoring the difficulties, altering the message, or simply giving up.

Importantly, the retrospective results from the post-task recalls identified 95 individual strategies, which allowed us to triangulate the data and proved to be an important data source for identifying strategies not present in the OCSI questionnaire or used in the debate tasks.

\section{Discussion of key findings}

In investigating the communication strategies used by 11 Chinese EAL learners in completing informal debate tasks, we found that, consistent with previous studies, participants used a wide range of strategies (eight strategy categories, 28 individual strategies, and 1947 total strategies identified, combining all sources of data elicited both during and following the speaking tasks).

The results from the OCSI questionnaire indicate that participants used nonverbal strategies most frequently (e.g., Idrus, 2016) and message abandonment least frequently (e.g., Ounis, 2016). The results from the identified communication strategies used in the informal debate tasks and the post-task recall, however, suggest that participants were frequent users of fluency- and accuracy-oriented strategies but rarely used translation strategies. The infrequent use of the latter is in line with previous findings, which have shown that learners with higher proficiency tend to use fewer own-language-based communication strategies (e.g., Abunawas, 2012) as they reach automaticity. Thus, the results of the identified observed and reported strategies elicited during and after task performance did not corroborate the OCSI findings. Possible explanations could be that (a) participants were not aware of their task-specific strategy use, (b) their responses to the questionnaire may not have reflected their actual strategic behaviours (Gao, 2007; Phakiti, 2003), (c) participants may have responded to different task requirements with different strategies, or (d) the questionnaire may not have been a reliable way to elicit possible variations in strategy use across tasks (Huang, 2013, 2014).

Regarding strategy use vis-à-vis proficiency levels, the literature shows mixed findings owing to different research contexts and methods of analysis (see Cohen \& Macaro, 2007). Results from the present study show that overall advanced learners resorted to communication strategies more often than high-intermediate 
learners, and especially in the categories of social-affective, negotiation of meaning, and message reduction and alteration. These findings are also in line with some studies suggesting that the selection of communication strategies tends to vary across or between proficiency levels (e.g., Abunawas, 2012; Liskin-Gasparro, 1996; Mirzaei \& Heidari, 2012; Paribakht, 1985), yet also contrast with more recent studies showing otherwise (e.g., Huang, 2013; Purpura, 1999; Swain et al., 2009). In this case, it seems that learners with higher oral production scores tended to use more strategies related to managing their emotions, to interact with others to negotiate meanings, and to modify their way of speaking when encountering communication problems (e.g., Mirzaei \& Heidari, 2012). Advanced learners' tendency to monitor and evaluate their use of communication strategies can be gleaned from their post-task strategy recall, as the following excerpt illustrates:

Reading more materials is useful to enlarge vocabulary. I think most times it works. Most listeners could get the point when I choose some simpler or more common words. But sometimes, the simpler words that I choose could not express the deep meaning which I would like to express. (P5, EE, Advanced)

The significant difference in the use of message reduction and alteration between the advanced and high-intermediate participants is worth noting. Advanced learners used strategies in this category, along with translation strategies, least often among the eight categories of communication strategies. This result is consistent with previous findings (e.g., Færch \& Kasper, 1980; Margolis, 2001; Zhao \& Intaraprasert, 2013), that is, that successful learners resort more frequently to achievement than avoidance strategies. Reasons for using avoidance strategies may be extremely complex and difficult to examine (Tarone, 1981), and the present study highlights the need to investigate further their use by learners of different proficiencies when speaking.

As for the use of communication strategies vis-à-vis disciplines, contrary to previous findings, our results detected no statistically significant differences between the EE and ED participants in any of the eight strategy categories. Yet the lack of statistical significance is not equivalent to a lack of practical significance (Huang, 2013). As Alderson (2004) pointed out, "Absence of evidence is not evidence of absence" (p. 476). This lack of statistical differences therefore does not necessarily mean that the results are not important or have no meaningful implications in reality. We did, however, detect a significant difference in individual strategies regarding use of clarifying stances between the EE and ED participants, with significantly greater use of this strategy by the ED group ( $\mathrm{Xu}$, 2017). This difference may be related to disciplinary variations in the kinds of writing and speaking tasks that learners in education often engage in. In addition, during the debates the ED learners, unlike the EE learners, did not share the same interpretations of the topic, which necessitated clarifying their stances in advancing their viewpoints.

Regarding the relationship between use of communication strategies and oral production, we identified statistically significant relationships between the frequency of 
strategy use and debate scores. Consistent with Nakatani's (2006) findings, speaking performance showed a significant positive relationship with the following strategy categories: social-affective, fluency-oriented, negotiation of meaning, accuracy-oriented, and message reduction and alteration. Significant positive relationships were also found between debate scores and the frequency of certain individual strategies, namely, yielding turns, referring to notes for fluency, exemplifying, clarifying meaning, referring to notes for accuracy, correcting others, and message reduction and alteration. This positive relationship between strategy use and language performance is well supported by previous studies (e.g., Zhao \& Intaraprasert, 2013), although it is also important to guard against overinterpretation of correlational findings since correlation does not mean causality.

We did not in this study focus on the actual effect of communication strategies on participants' speaking performance. Furthermore, the quality of strategy use in relation to task, context, and learner variables mattered more than quantity or frequency of use. One may postulate that the advanced participants used more communication strategies because they had greater awareness of their use of these strategies in relation to their oral production. This may be seen in their post-task recall, in which they made more references to communication strategies in speaking $(M=10.6$ vs. $M=6.83)$. Further, as measured by the average number of turns taken by the two groups (advanced: $M=79.80$; high-intermediate: $M=39.67$ ), the high-intermediate participants were clearly dealing with factors beyond language proficiency. Awareness of mental processes related to planning, monitoring, and/or evaluating their strategy use may have increased their cognitive load and had a direct impact on the amount of attention they could devote to performing the speaking tasks (Sweller, Ayresm, \& Kalyuga, 2011). Therefore, without examining other mediating factors, such as individual learner variables, task types, and communication contexts, any claims about a relationship between strategy use and proficiency level risks a generalization that may be an oversimplification.

\section{Implications, limitations, and future research directions}

Our findings provide some insights into the strategic behaviours of Chinese EAL learners when performing speaking tasks involving informal debates. For instructors unable to incorporate strategy-based instruction for various reasons, being aware of strategy use and engaging in evaluation could potentially heighten such awareness among learners of lower proficiency. This awareness may in turn provide learners with tools to enhance their metacognition and articulate their own learning process and outcomes in ways that could improve their performance of subsequent tasks. As Kolencik and Hillwig (2011) stated, "Effective learners do not just stumble onto success" (p. 7). Learners who are more aware of their thought processes and are able to adapt these processes to specific goals are on the pathway to regulating their own learning. The following excerpt from the post-task strategy recall illustrates how learners commonly and explicitly identify various communication issues, which, in language teaching, are windows into ways instructors may help learners, regardless of level, in developing strategies to deal with the challenges that are meaningful to them: "I have so many problems: grammatical rules, Chinese accent, 
improper word order, grammatical problems like emphasis, tense, etc. I still need improvement.. .. I am really short of words and sentence diversification" (P3, EE, High-intermediate).

A search in the literature reveals ample evidence that metacognition and selfregulation are key to learning (e.g., Bartimote-Aufflick, Bridgeman, Walker, Sharma, \& Smith, 2016; Chen, Chavez, Ong, \& Gunderson, 2017; Lang, 2012). As cognitive neuroscientist Fleming (2014) once explained: "Metacognition is how we identify our limitations and compensate for them... ultimately metacognition serves as a foundation for learning and success" (p. 32). Metacognition, or insights into our own thoughts, involves second- or higher-order thinking engaged in active control over our cognitive processes. It is well recognized no single strategy or set of strategies works equally well for all learners across all tasks and contexts. Strategy use is inherently tied to the user, the task at hand, and the context of the task performed. The inductive approach used in this study of incorporating the strategic component into learning provides flexibility that may facilitate the pursuit of individual paths of discovery. Rather than explicitly teaching how, when, and why certain strategies can be used to facilitate language learning, the concern is more about providing the necessary mediational tools (e.g., task-based reflection) that will help learners engage in an iterative, problem-solving process of metacognitive dialogues to determine whys, whens, and hows through experiment, monitoring, and evaluation.

No studies are without limitations. First, the sample size (reflecting the graduate class size at the institution where the participants were recruited), debate topics, and task types of this study were all variables that could have affected oral production and strategy use. Small-sample studies may also limit the use of statistical tools to make generalizable quantitative statements; nonetheless, they can still contribute to meta-analytic results that may be generalized with confidence. As for topic familiarity, although the topics were sourced from standardized instruments and there were preferences for task types, the topics resembled what graduate students commonly encounter when communicating in academic settings.

Second, although we considered both the pre-test and actual oral production during the debates when assessing the learners' language proficiency, both were administered in non-testing situations. One may argue that such an assessment may more validly reflect learners' oral production; one may also rightly question the validity of an assessment, though systematic, conducted in a nonstandardized way.

Finally, despite calls for researchers to use multiple data sources in validating their findings (e.g., Huang, 2013; Gao, 2007; Khan \& Victori, 2011; Phakiti, 2003), the challenges associated with analyzing strategy use remain. Both the validity and reliability of OCSI for non-Japanese EFL students have been questioned (e.g., Yaman \& Irgin, 2013; Pawlak \& Waniek-Klimczak, 2014). Modifying the OCSI to suit the present study required us to examine its items critically, the process of which drew our attention to problematic items and categories. Given the body of research and non-corroborative results from different sources, relying solely on perceived strategy use elicited through general self-report measures of strategies 
and using non-task-, non-learner-, and non-context-specific instruments deserve serious reconsideration. Also, in addition to the examples provided in the Methods section, the purpose for using a certain strategy can influence how it is categorized. For example, the individual strategy item "I pay attention to my pronunciation," categorized under fluency-oriented strategies, could also be placed under accuracy-oriented strategies, depending on the reason the strategy was used while performing the task. Therefore, interpreting learners' use of strategies based only on data generated from such instruments without understanding their underlying intentions, which could be learned through a member check, may contribute to the "rather inconsistent and elusive" nature of strategies, to use Dörnyei and Skehan's (2003) description, and so may warrant scrutiny.

As with any study, often some questions are answered, while other findings give rise to more questions. One direction for further study involves developing task-based strategy questionnaires for researchers examining strategic behaviours in relation to specific tasks. The coding of strategies and the establishing of intercoder reliability based on actual task performance that involve large sample sizes and can provide sufficient power for statistical analysis is not only time consuming, but also not always feasible (Huang, 2013). Developing and validating a task-based strategy inventory (defining task as one involving "individuals in using language [to achieve] a particular goal or objective in a particular situation," Bachman \& Palmer, 1996, p. 44) that draws on findings from studies exploring communication strategies used in performing various task types could achieve greater robustness and produce empirical evidence regarding the patterns of strategic behaviours across tasks used by learners of varying proficiency.

Another direction for future studies involves looking into the social and affective strategies used by learners. Even though considerable studies have reported the importance of socio-affective strategies (e.g., Fandiño Parra, 2010; Habte-Gabr, 2006), reporting about their use has always been minimal, possibly owing to the methods used to elicit strategy use data. In turn, little attention has been paid to the role these strategies play in speaking performance. In this study we have identified significant relationships between such strategies and learners' proficiency levels and speaking performance; this line of research thus merits further exploration in future studies involving larger sample sizes.

\section{Conclusion}

This study is unique in examining the relationships between communication strategy use and learners' speaking performance in completing informal debate tasks across two disciplines by learners at the graduate level. It also responds to the call to move beyond using questionnaire data alone and thereby to enhance the validity of strategy use data. Not only has the study shed light on strategy use, but it also, importantly, underscores issues surrounding the methods used to glean patterns of strategic behaviours. The study has also sought to realize the benefits of triangulation in seeking to find new pathways to understanding a phenomenon, and in so doing has revealed unique discoveries that could help provide a fuller understanding of questions researchers have been seeking answers to since the seminal work of Rubin and Stern in the 1970s and of Færch and Kasper in the 1980s. 


\section{Appendix}

Table 5 Coding Scheme

\begin{tabular}{|c|c|}
\hline Individual Strategies & Definition \\
\hline \multicolumn{2}{|c|}{$\begin{array}{l}\text { Social-Affective Strategies: Participants' strategic behaviours or actions to encourage themselves to continue } \\
\text { to communicate orally with others }\end{array}$} \\
\hline Lowering anxiety & Trying to relax to lower anxiety in speaking \\
\hline Self-encouragement & Encouraging oneself through positive statement \\
\hline Empathizing with others & Using rhetorical questions to seek emotional resonance \\
\hline Asking for assistance & Asking for assistance when encountering difficulties \\
\hline Turn-yielding_-pausing & Pausing to yield a turn \\
\hline Turn-yielding—signalling & Using a filler to signal the end of turns \\
\hline Turn-requesting一demanding & Requesting a turn through asking questions \\
\hline Turn-requesting-raising voice & Raising voice to grab attention in order to take turns \\
\hline \multicolumn{2}{|c|}{ Fluency-Oriented Strategies: Participants' strategic behaviours or actions to speak more fluently } \\
\hline Using fillers & Using fillers to gain time when encountering problems \\
\hline Referring to notes for fluency & Referring to notes to speak more fluently \\
\hline Rehearsing & Mentally rehearsing what to say \\
\hline Stalling & Pausing for a few seconds to gain some time \\
\hline
\end{tabular}

Negotiation of Meaning: Participants' strategic behaviours or actions to interact with interlocutors in order to improve comprehension/comprehensibility
Repeating
Repeating speech to be understood
Exemplifying
Giving examples to make oneself understood
Approximating
Using synonyms to clarify meaning
Analogy
Using an analogy to make oneself understood
Elaborating
Elaborating to clarify meaning
Clarifying stance
Clarifying one's position when there is misunderstanding
Comprehension checks/
Making comprehension checks through questions
seeking clarification
Clarifying meaning when there is misunderstanding
Clarifying meaning

Accuracy Orientated Strategies: Participants' strategic behaviours or actions to correct expressions when making mistakes
Self-correction for accuracy
Correcting oneself to enhance accuracy
Self-correction for preciseness
Correcting oneself to enhance precision
Referring to notes for accuracy
Referring to notes enhance accuracy
Correcting others
Correcting others' speech
Chunking
Chunking complicated sentences into simpler and shorter sentences
Message reduction and
Reducing an original message to avoid a communication breakdown alteration

Nonverbal Strategies: Participants' strategic behaviours or actions to use eye contact, gestures, or facial expressions to give hints or help the listener guess what they want to say

\begin{tabular}{|c|c|}
\hline Eye contact & $\begin{array}{l}\text { Making eye contact with others to seek agreement or when } \\
\text { encountering problems }\end{array}$ \\
\hline $\begin{array}{l}\text { Gesturing-to indicate } \\
\text { meaning }\end{array}$ & Using gestures to present the meaning of certain words \\
\hline $\begin{array}{l}\text { Gesturing-to indicate } \\
\text { problems }\end{array}$ & Using gestures to indicate that one has encountered difficulties \\
\hline Gesturing—directing & Pointing or using certain gestures to speak to a specific person \\
\hline Facial expressions & $\begin{array}{l}\text { Using facial expressions to indicate disagreement or difficulties either in } \\
\text { understanding or expressing }\end{array}$ \\
\hline
\end{tabular}


Table 5 Coding Scheme (Continued)

\begin{tabular}{|c|c|}
\hline Individual Strategies & Definition \\
\hline \multicolumn{2}{|c|}{$\begin{array}{l}\text { Message Abandonment Strategies: Participants' strategic behaviours or actions to give up their attempts to } \\
\text { communicate }\end{array}$} \\
\hline Avoidance & Giving up trying to express intended meaning, resulting in avoidance \\
\hline \multicolumn{2}{|c|}{$\begin{array}{l}\text { Translation: Participants' strategic behaviours to translate directly from the first language to the target } \\
\text { language }\end{array}$} \\
\hline Translating & Translating from Chinese to English \\
\hline
\end{tabular}

\section{Availability of data and materials}

Available upon request.

\section{Authors' contributions}

Conceptualization: Author 1 and Author 2. Data collection: Author 1. Data Analysis: Author 1 and reviewed by Author 2. Writing —original report: Author 1 and reviewed by Author 2. Writing—-manuscript and revisions: Author 2. Both authors read and approved the final manuscript.

\section{Competing interests}

The authors declare that they have no competing interests.

\section{Publisher's Note}

Springer Nature remains neutral with regard to jurisdictional claims in published maps and institutional affiliations.

Received: 23 February 2018 Accepted: 4 July 2018

Published online: 27 August 2018

\section{References}

Abunawas, S. N. (2012). Communication strategies used by Jordanian EFL learners. Canadian Social Science, 8(4), 178193.

Albino, G. (2017). Improving speaking fluency in a task-based language teaching approach: The case of EFL learners at PUINIV-Cazenga. Sage Open, 7(2). doi/full/https://doi.org/10.1177/2158244017691077

Alderson, P. (2004). Absence of evidence is not evidence of absence. British Medical Journal, 328(7438), 476-477.

An, M., \& Nathalang, S. S. (2010). Use of communication strategies by Chinese EFL learners. Chinese Journal of Applied Linguistics, 33(3), 110-125.

Baker, S. C., \& Maclntyre, P. D. (2003). The role of gender and immersion in communication and second language orientations. Language Learning, 53(1), 65-96.

Bartimote-Aufflick, K., Bridgeman, A., Walker, R., Sharma, M., \& Smith, L. (2016). The study, evaluation, and improvement of university student self-efficacy. Studies in Higher Education, 41(11), 1918-1942.

Bialystok, E. (1990). Communication strategies: A psychological analysis of second-language use. Oxford: Basil Blackwell.

Brown, I. B. (2013). Relationships between L2 motivation and oral communication strategies among Japanese university EFL students. Bulletin of Joetsu University of Education, 32(2), 273-283.

Canale, M. (1980). Theoretical bases of communicative approaches to second language teaching and testing. Applied Linguistics, 1(1), 1-47.

Canale, M. (1983). From communicative competence to communicative language pedagogy. In J. C. Richards \& R. W. Schmidt (Eds.), Language and communication (pp. 2-27). London: Longman.

Chang, S. J. (1991). A study of learning behavior of Chinese students at the University of Georgia and the relation of those behaviors to oral proficiency and other factors (doctoral dissertation). Athens: University of Georgia.

Chen, H. W. (2009). Oral communication strategies used by English major college students in Taiwan. (Master's thesis). Chaoyang University of Technology, Taichung, Taiwan.

Chen, P., Chavez, O., Ong, D. C., \& Gunderson, B. (2017). Strategic resource use for learning: A self-administered intervention that guides self-reflection on effective resource use enhances academic performance. Psychology Science, 28(6), 774-785.

Chen, S.-Q. (1990). A study of communication strategies in interlanguage production by Chinese EFL learners. Language Learning, 40(2), 155-187.

Chen, Y. (2006). From common core to specific. The Asian ESP Journal, 2(1). Retrieved from https://www.asian-espjournal.com/?p=123.

Cohen, A. D., \& Macaro, E. (Eds.). (2007). Language learner strategies: Thirty years of research and practice. Oxford: Oxford University Press.

Corder, S. P. (1983). Strategies of communication. Strategies in interlanguage communication, 15-19.

Costello, A. B., \& Osborne, J. W. (2005). Best practices in exploratory factor analysis: Four recommendations for getting the most from your analysis. Practical Assessment, Research \& Evaluation, 10(7), 1-9 Retrieved from http://pareonline. net/pdf/v10n7.pdf.

Dörnyei, Z. (1995). On the teachability of communication strategies. TESOL Quarterly, 29(1), 55-85.

Dörnyei, Z., \& Skehan, P. (2003). Individual differences in second language learning. In C. J. Doughty \& M. H. Long (Eds.), The handbook of second language acquisition (pp. 589-630). Oxford: Blackwell. 
Ellis, R. (1994). The study of second language acquisition. Oxford: Oxford University Press.

Færch, C., \& Kasper, G. (1980). Processes and strategies in foreign language learning and communication. Interlanguage Studies Bulletin - Utrecht, 5(1), 47-118.

Færch, C., \& Kasper, G. (1983). Strategies in interlanguage communication. Harlow: Longman.

Fandiño Parra, Y. J. (2010). Explicit teaching of socio-affective language learning strategies to beginner EFL students. Ikala, Revista de Lenguaje y Cultura, 15(24), 145-169.

Faucette, P. (2001). A pedagogical perspective on communication strategies: Benefits of training and an analysis of English language teaching materials. Second Lanquage Studies, 19(2), 1-40.

Fleming, S. (2014). The power of reflection. Scientific American Mind, 25, 30-37.

Fulcher, G. (2003). Testing second language speaking. London: Longman/Pearson Education.

Gao, X. S. (2007). Has language learning strategy research come to an end? A response to Tseng et al. (2006). Applied Linguistics, 28(4), 615-620.

Ghout-Khenoune, L. (2012). The effects of task type on learners' use of communication strategies. Procedia - Social and Behavioral Sciences, 69, 770-779.

Guhlemann, M. (2011). Personality, motivation and communication strategy use: Individual differences in the language classroom (Master's thesis). Retrieved from https://kb.psu.ac.th:8443/psukb/bitstream/2010/5866/1/311751.pdf

Habte-Gabr, E. (2006). The importance of socio-affective strategies in using EFL for teaching mainstream subjects. The Journal of Humanizing Language Teaching, 8(5) Retrieved from http://www.hltmag.co.uk/sep06/sart02.htm.

Hall, D. (2011). Debate: Innovative teaching to enhance critical thinking and communication skills in healthcare professionals. The Internet Journal of Applied Health Sciences and Practice, 9(3), 1-8.

Huang, J. (2004). Voices from Chinese students: Professors' use of English affects academic listening. College Student Journal, 38(2), 212-230.

Huang, J. (2005). Challenges of academic listening in English: Reports by Chinese students. College Student Journal, 39(3), 553-569.

Huang, L.-S. (2010). Do different modalities of reflection matter? An exploration of adult second-language learners' reported strategy use and oral language production. System, 38(2), 245-261.

Huang, L.S. (2012). Use of oral reflection in facilitating graduate EAL students' oral language production and strategy use: An empirical action research. International Journal for the Scholarship of Teaching and Learning, 6(2), 1-22.

Huang, L.-S. (2013). Cognitive processes involved in performing the IELTS speaking test: Respondents' strategic behaviours in simulated testing and non-testing contexts, pp. 51. IELTS research report series. Retrieved from https:/www.ielts.org/teaching-and-research/research-reports/online-series-2013-1

Huang, L.-S. (2014). Video-stimulated verbal recall: A method for researching cognitive processes and strategic behaviours. Sage Cases in Methodology Retrieved from https://goo.gl/zuWyyc.

Idrus, H. (2016). Enhancing oral presentation skills of ESL students: The use of oral communication strategies. In S. F. Tang \& L. Logonnathan (Eds.), Assessment of learning within and beyond the classroom (pp. 437-446). Singapore: Springer Science+Business Media Singapore.

Kassim, H., \& Radzuan, N. R. M. (2008). Resolving conflict: Enhancing engineering students' English. The International Journal of Learning, 14(11), 51-60.

Kennedy, K. (2017). International students entering Canada up 22\% to 270,000. The Pie News. Retrieved from https:// thepienews.com/news/canada-new-international-students-270000/

Khan, S., \& Victori, M. (2011). Perceived vs. actual strategy use across three oral communication tasks. International Review of Applied Linguistics in Language Teaching, 49(1), 27-53.

Kolencik, P. L., \& Hillwig, S. A. (2011). Encouraging metacognition. New York: Peter Lang

Lang, J. M. (2012). Metacognition and student learning. The Chronicle of Higher Education. Retrieved from http://goo.gl/sclBC

Lennon, P. (2008). Contrastive analysis, error analysis, interlanguage. In S. Gramley \& V. Gramley (Eds.), Bielefeld introduction to applied linguistics (pp. 51-60). Bielefeld: Aisthesis.

Linebach, J. A., Tesch, B. P., \& Kovacsiss, L. M. (2014). Nonparametric statistics for applied research. New York: Springer Science+Business Media, LLC.

Liskin-Gasparro, J. E. (1996). Circumlocution, communication strategies, and the ACTFL proficiency guidelines: An analysis of student discourse. Foreign Language Annals, 29(3), 317-330.

Macaro, E. (2006). Strategies for language learning and for language use: Revising the theoretical framework. The Modern Language Journal, 90(3), 320-337.

Margolis, D. P. (2001). Compensation strategies by Korean students. The PAC Journal, 1(1), 163-174.

Maroof, D. A. (2012). Statistical methods in neuropsychology: Common procedures made comprehensible. Boston: Springer Science and Business Media.

Miles, M. B., Huberman, A. M., \& Saldana, J. (2014). Qualitative data analysis: A methods sourcebook. Thousand Oaks: Sage.

Mirzaei, A., \& Heidari, N. (2012). Exploring the use of oral communication strategies by (non)fluent L2 speakers. The Journal of Asia TEFL, 9(3), 131-156.

Mochizuki, A. (1999). Language learning strategies used by Japanese university students. RELC Journal, 30(2), 101-113.

Myles, J. (2009). Oral competency of ESL technical students in workplace internships. TESL-EJ, 13(1), 1-24.

Myles, J., Quian, J., \& Chen, L. (2002). International and new immigrant students' adaptations to the social and cultura life at a Canadian university. In Connections \& Complexities: The Internationalization of Canadian Higher Education. Winnipeg: Center for Research and Development in Higher Education.

Nakatani, Y. (2006). Developing an oral communication strategy inventory. The Modern Language Journal, 90(2), 151-168.

O'Malley, J. M., \& Chamot, A. U. (1990). Learning strategies in second language acquisition. Cambridge: Cambridge University Press.

Ounis, T. (2016). Exploring the use of oral communication strategies by high and low proficiency learners of English: Tunisian EFL students as a case study. International Journal of Humanities and Cultural Studies, 3(1), 1077-1098.

Paribakht, T. (1985). Strategic competence and language proficiency. Applied Linguistics, 6(2), 132-146.

Pawlak, M., \& Waniek-Klimczak, E. (Eds.). (2014). Issues in teaching, learning and testing speaking in a second language. New York: Springer. 
Peacock, M., \& Ho, B. (2003). Student language learning strategies across eight disciplines. International Journal of Applied Linguistics, 13(2), 179-200.

Pett, M. A. (2016). Nonparametric statistics for health care research: Statistics for small samples and unusual distributions (2nd ed.). Thousand Oaks: Sage.

Phakiti, A. (2003). A closer look at gender and strategy use in L2 reading. Language Learning, 53(4), 649-702.

Purpura, J. E. (1999). Learner strategy use and performance and language tests: A structural equation modelling approach. Cambridge: University of Cambridge Local Examinations Syndicate and Cambridge University Press.

Rossiter, M. J. (2003). "It's like chicken but bigger": Effects of communication strategy in the ESL classroom. Canadian Modern Language Review, 60(2), 105-121.

Saziye, Y., \& Pelin, I. (2013). The validity and reliability studies of the oral communication strategy inventory. H. U. Journal of Education, 28(1), 417-427.

Selinker, L. (1972). Interlanguage. IRAL - International Review of Applied Linguistics in Language Teaching, 10(1-4), 209-232.

Skehan, P. (1998). A cognitive approach to language learning. New York: Oxford University Press.

Smith, B. (2003). The use of communication strategies in computer-mediated communication. System, 31(1), 29-53.

Sun, W., \& Chen, G.-M. (1999). Dimensions of difficulties mainland Chinese students encounter in the United States. Intercultural Communication Studies, 9(1), 19-30.

Swain, M., Huang, L.-S., Barkaoui, K., Brooks, L., \& Lapkin, S. (2009). The speaking section of the TOEFL iBTM (SSTiBT): Testtakers' reported strategic behaviors (TOEFL iBT TM Research Series No. TOEFLiBT-10). Princeton, NJ: Educational Testing Service (ETS), Pp. vi+128. Retrieved from https://onlinelibrary.wiley.com/doi/abs/10.1002/j.2333-8504.2009. tb02187.x

Sweller, J., Ayresm, P., \& Kalyuga, S. (2011). Cognitive load theory. New York: Springer-Verlag.

Tan, K. H., Nor, F. M. N., \& Mohd, N. J. (2012). Oral communication strategies among international students at UKM. GEMA Online Journal of Language Studies, 12(3), 831-848.

Tarone, E. (1981). Some thoughts on the notion of communication strategy. TESOL Quarterly, 15(3), 285-295.

Teng, H. C. (2011). Communication strategy use of EFL college students. In A. Stewart (Ed.), JALT 2010 conference proceedings (pp. 975-985). Tokyo: Japan Association for Language Teaching.

Tyler, A. E., Takada, M., Kim, Y., \& Marinova, D. (2005). Language in use: Cognitive and discourse perspectives on language and lanquage learning. Washington, D.C.: Georgetown University Press.

Wan, G. (2001). The learning experience of Chinese students in American universities: A cross-cultural perspective. College Student Journal, 35(1), 28-44.

Wang, L. F. (2000). Review of communication strategies in SLA abroad. FL Teaching and Research, 2, 124-131.

$\mathrm{Xu}, \mathrm{X}$. (2017). An analysis of stance and voice in research articles across Chinese and British cultures, using the appraisal framework (Doctoral dissertation). Retrieved from https://goo.gl/UYGnk6.

Yaman, S., \& Irgin, P. (2013). The validity and reliability studies of the oral communication strategy inventory. Hacettepe University Journal of Education, 28(1), 417-427.

Yang, D., \& Gai, F.P. (2010). Chinese learners' communication strategies research: A case study at Shandong Jiaotong university. Cross-Cultural Communication, 6(1), 56-81.

Yoshida-Morise, Y. (1998). The use of communication strategies in language proficiency interviews. In R. Young \& W. He (Eds.), Talking and testing: Discourse approaches to the assessment of oral proficiency (pp. 205-238). Amsterdam: John Benjamins.

Zhao, T., \& Intaraprasert, C. (2013). Use of communication strategies by tourism-oriented EFL learners in relation to gender and perceived language ability. English Language Teaching, 6(7), 46-59.

\section{Submit your manuscript to a SpringerOpen ${ }^{\circ}$ journal and benefit from:}

- Convenient online submission

- Rigorous peer review

- Open access: articles freely available online

- High visibility within the field

- Retaining the copyright to your article

Submit your next manuscript at $\mathbf{s p r i n g e r o p e n . c o m ~}$ 